\title{
E-Sports, herdeiros de uma tradição
}

\section{Tarcízio Macedo}

Doutorando; Universidade Federal do Rio Grande do Sul, Porto Alegre, RS, Brasil

tarcizio.macedo@bol.com.br

\section{Thiago Falcão}

Doutor; Universidade Federal do Maranhão, Imperatriz, MA, Brasil

thfalcao@gmail.com

\section{Resumo}

Este artigo empreende uma discussão de base histórica acerca do fenômeno do jogo digital competitivo organizado, conhecido popularmente como e-Sport. Seu intuito é prover um referencial teórico que enderece o aspecto híbrido dos e-Sports, considerando que esse faz convergir os campos da Comunicação, Game Studies, Filosofia e Sociologia do Esporte. 0 artigo, que endereça o e-Sport como legítimo herdeiro de uma tradição esportiva, investiga dois aspectos específicos da prática: (1) uma genealogia que, acreditamos, conecta-os a uma tradição milenar; e (2) uma ontologia que sublinha sua condição experiencial necessariamente midiática.

\section{Palavras-chave}

Games. E-Sports. Esporte. Competição. Game Studies.

\section{Introdução}

A discussão em torno do fenômeno dos e-Sports, termo comumente usado para designar o esporte eletrônico, tem se tornado particularmente recorrente no Brasil - e não só em seu aspecto acadêmico, mas em uma repercussão social mais ampla, que implica tanto em um endereçamento frequente por parte dos meios de comunicação quanto em um princípio de fomento e aceitação mais abrangente, verificado a partir da criação de times e instituições dedicadas à prática. Essa condição de recorrência surge como consequência direta de dois fatores que enquadram a experiência dos video games no país: primeiro, sua irrestrita aceitação, ao passo que o Brasil figura como principal mercado em consumo de 
games na América Latina, além de ser também um dos mais relevantes mercados de atuação para empresas do gênero no mundo ${ }^{1}$; em seguida, pelo fato de que subsiste um relacionamento de ordem espetacular entre esporte e meios de comunicação, particularmente proeminente no cenário midiático do país. Assim, discussões ao redor de termos como "esporte eletrônico" ou "professional gaming" (pro gaming) 2 tornaram-se lugar comum para o espectro da mídia especializada, seja em video games ou em esportes de forma mais geral.

Essa conjuntura implica em uma percepção incontornável: a de que o enquadramento dado aos e-Sports tende a se apropriar de uma lógica e linguagem empreendida pelo jornalismo esportivo na transmissão de esportes em seu aspecto mais amplo. Transmissões provenientes de canais consolidados, como ESPN ou SporTV, e streams específicas realizadas por empresas do gênero, como Blizzard Entertainment ou Riot Games, utilizam-se de um formato que sempre busca replicar o do jornalismo esportivo (AMÉRICO, 2014; MACEDO, 2018b), com profissionais explicando e discutindo as ações dos jogadores. Podemos sugerir, assim, que se compõe um fenômeno de "esportificação" ${ }^{3}$ dos jogos digitais ${ }^{4}$.

Nesse contexto, o presente artigo debruça-se sobre um cenário de pesquisa que, embora não seja por si recente (BOROWY, 2012; BOROWY; JIN, 2013; TAYLOR, T., 2012; TAYLOR, N., 2015), envolve a consolidação de um fenômeno de profissionalismo dos jogos digitais, além da consequente ascensão do esporte eletrônico como um empreendimento ao qual se agrega uma dimensão do esporte. Esta reflexão parte de um esforço interdisciplinar que faz convergir os campos da Comunicação, da Filosofia e Sociologia do Esporte, bem como o campo dos Game Studies, sobretudo ao sublinhar que o enquadramento adotado para se referir aos $e$-Sports na academia negligencia um aspecto próprio do esporte, mesmo em um momento no qual se dispensa considerável atenção para o fenômeno (BOROWY, 2012; BOROWY; JIN, 2013; TAYLOR, T., 2012; TAYLOR, N., 2009, 2015).

O objetivo não é reviver o controverso debate em torno da ideia do jogo digital como esporte, que implica como o conceito de $e$-Sport se adequa à definição e às características do

\footnotetext{
1 Conforme pesquisa da consultora Newzoo, realizada em dezembro de 2017, o Brasil é o segundo maior mercado de video games da América Latina e o 12º maior do mundo. Disponível em: https://bit.ly/1nkJqKD. Acesso em: 5 jun. 2018.

2 Trata-se de mais uma expressão utilizada para se reportar ao esporte eletrônico, cujo significado, em livre tradução, é jogo profissional. A despeito da expressão e-Sport ser ainda mais recorrente, utilizaremos esse termo para evitar a sua repetição demasiada no decorrer do texto.

3 O sociólogo francês Pierre Parlebas (1999) define a "esportificação" como um processo social e institucional pelo qual uma determinada atividade ludomotora adquire o status de esporte.

4 Outro termo utilizado é "ciberesporte" (cybersport), embora não seja tão recorrente quanto os dois anteriores.
} 
esporte moderno - não porque não seja algo necessário, mas porque alguns sociólogos e filósofos do esporte, como Dennis Hemphill (2005), Kalle Jonasson e Jesper Thiborg (2010), Nicolas Besombes (2016a, 2016b), já o empreenderam de forma competente, e, na medida do possível, acionaremos esse debate para problematizar algumas questões.

Assim, nossa abordagem resgata definições institucionais do esporte no intuito de construir uma crítica acerca da gênese do e-Sport. Nesse contexto, acreditamos que a prática do esporte eletrônico constitui uma nova fase dos esportes (JONASSON, 2013, 2016). Desenvolvemos, portanto, uma análise constitutiva e sistemática do fenômeno do pro gaming como esporte, atualizando discussões que figuram de forma profícua - ainda que introdutória - no âmbito internacional dos Game Studies, mas que são previsivelmente negligenciadas no contexto brasileiro. Esse esforço demonstra e justifica a possibilidade do objeto $e$-Sport no âmbito das pesquisas em Comunicação, na medida em que aciona um debate sobre o esporte eletrônico como um fenômeno e produto de uma cultura midiática que faz convergir as dimensões da mídia e do esporte, até então ignoradas ou pouco consideradas nos Game Studies e no próprio campo da Comunicação.

Neste artigo, definimos o e-Sport como uma propagação legítima do esporte convencional enquanto modalidade esportiva. Nele, o competidor encontra-se conectado a uma máquina que trata de desenvolver grande parte do trabalho, a competição tem vencedores e perdedores e é essencial muita habilidade corporal e um engajamento cognitivo complexo para participar dessas disputas como jogador. Em síntese, o e-Sport surge como uma prática de evento esportivo público, mediado tecnologicamente, com base na competição organizada entre jogadores através da incorporação das suas performances eles desenvolvem e treinam habilidades mentais e físicas no uso e interação com as Tecnologias da Informação e Comunicação (TICs), especialmente, nesse caso, os jogos digitais.

\section{Breve história dos e-Sports}

A noção de competição é, sem dúvidas, um dos mais básicos pilares da discussão sobre o jogo; não é possível discutir sobre ele, em sua forma contemporânea, sem reconhecer lugares de antagonismo: forças opostas que disputam um prêmio específico. Johan Huizinga (1938) explicou, há muito, que este aspecto agonístico não passa de uma matiz específica em todo um espectro do jogo: a própria cultura depende das dinâmicas de 
fuga, subversão e apropriação que os múltiplos sentidos da palavra play esforçam-se para endereçar.

Ainda assim, o convite ao jogo geralmente implica em vencedores e perdedores, e os video games, no decorrer de sua história, ilustraram essa característica de forma muito veemente. De campeonatos de Pac-Man (Namco, 1980) e outros arcades à própria essência dos jogos de luta da década de 1990 - entre eles Street Fighter (Capcom, 1987) e Fatal Fury (SNK, 1991), jogadores foram usualmente considerados oponentes diametrais5. Esse histórico sugere que é possível considerar a organização do fenômeno do jogo digital competitivo organizado como uma indústria de mídia de entretenimento legítima e viável. Ainda assim, sua história é, no mínimo, errática (BOROWY, 2012; BOROWY; JIN, 2013; TAYLOR, N., 2015; TAYLOR, T., 2012).

O processo de esportificação dos jogos digitais competitivos está intimamente relacionado com o desenvolvimento dos e-Sports. Assim, ao nos debruçarmos sobre a relação histórica entre mídia, esporte e tecnologia, podemos estabelecer uma crítica da experiência midiática contemporânea do esporte. Esse percurso, é necessário sublinhar, reforça a compreensão de que os e-Sports são herdeiros de uma tradição muito mais longa e rica de jogo competitivo organizado, e não um simples fenômeno de entretenimento adolescente.

Essa história, segundo T. L. Taylor (2012), inicia-se com a histórica importância das casas de fliperama (arcades) na década de 1980 para a impulsão da prática competitiva entre jogadores nos video games, particularmente atrelada - acreditamos - a uma estratégia promocional para comercialização dos primeiros jogos em arcades e consoles domésticos. Michael Borowy e Dal Yong Jin (2013) são mais específicos ao discutir o desenvolvimento histórico do jogo digital competitivo organizado durante os anos 1980, particularmente nos EUA. Ao examinarem as origens do e-Sport como um evento comercializado e uma mercadoria experiencial, eles consideram que esse período representa uma era transitória que contribui para distintas fases nas áreas de esportes, tecnologia e marketing, resultando na propagação da prática do ciberatletismo competitivo contemporâneo.

Para Borowy e Jin (2013), o e-Sport combina diferentes fatores, articulando a cultura mais ampla dos jogadores, a história dos esportes espetaculares, uma economia emergente centrada na experiência e um encadeamento de práticas de consumo, cujo crescimento foi

\footnotetext{
5 Naturalmente, formas de jogo colaborativo surgiram ainda na década de 1970, mas essas colocam em evidência outros aspectos, em seu desenvolver. Sobre essa discussão, ver Lisbeth Klastrup (2003).
} 
proporcional ao do marketing de eventos para arcades e consoles domésticos como um tipo de estratégia promocional, tornando-se, a partir do início dos anos 2000, uma característica relevante para o que os autores chamam de "cultura geral do jogador" (2013, p. 2254, tradução nossa).

Se, em seus primeiros dias, os jogos de computador eram reservados apenas a laboratórios universitários, uma variedade de novas possibilidades fez-se presente com a migração dos jogos digitais para os arcades. T. Taylor (2012) sublinha que a inserção de uma lista de pontuação foi o primeiro vetor para um comportamento competitivo nos arcades. Essa simples, porém revolucionária decisão de design transformou o jogo em uma competição contínua.

Assim, ainda que a história do pro gaming esteja mais relacionada ao jogo competitivo face a face em arcades e aos primeiros consoles domésticos reconhecidamente uma estratégia promocional para os primeiros video games - do que aos jogos em rede via internet, como apontam T. L. Taylor (2012) e Borowy e Jin (2013), subsiste um argumento de que este último contexto também é significativo, uma vez que reforça que os games, desde meados de sua origem, estabeleceram uma relação significativa com a competição.

T. L. Taylor (2012) também empreende uma análise histórica acerca de como o jogo competitivo consiste em uma prática que remonta várias décadas, ainda que demarque equivocadamente a década de 1980 como inaugural $^{6}$. Conforme a autora, os jogos de luta são, até hoje, saudados como o gênero precursor do pro gaming - não obstante se trate, a nosso ver, de uma percepção equivocada ${ }^{7}$. Nicholas Taylor (2015) argumenta ainda que a espectatorialidade do jogo competitivo remonta a experiência nas casas de fliperama (arcades) e, posteriormente, nos grupos de Local Arena Network (LAN) - rede de área local na América do Norte e na Europa durante a década de 1980, reforçando o papel central desempenhado pelos espectadores nos jogos digitais e na consolidação de uma comunidade voltada para a competição.

Por volta da década de 1980 (TAYLOR, T., 2012), já era possível observar tentativas de impulsionar essa prática para um contexto mainstream. 0 jogo competitivo sofreu, durante essa década, transformações do crescente apelo das versões domésticas dos video

\footnotetext{
6 O jogo competitivo como uma atividade de jogadores e espectadores formais já acontecia desde meados de 1970 (MACEDO, 2018a). Para maiores discussões, atentar para o capítulo "Breve introdução à história dos e-Sports" em Tarcízio Macedo (2018a).

${ }^{7}$ Antes mesmo da criação dos jogos de luta, determinados títulos de arcades e consoles domésticos (de tiro e espaçonaves, por exemplo, mas não limitados a estes) já anunciavam o fenômeno dos e-Sports no decorrer dos decênios de 1970 e 1980.
} 
games, os consoles. 0 ambiente do lar passou a ser o ponto principal de encontro e competição entre amigos e familiares, e, com essa nova dinâmica, o aspecto competitivo dos video games sofreu transformações à medida que eles cresciam e tornavam-se uma atividade mais caseira (TAYLOR, T., 2012). A primeira competição de video games em grande escala foi realizada em 1980 pela Atari, produtora do video game Space Invaders (Atari, 1978), embora torneios menores já fossem vistos desde o fim da década de 1970. 0 National Space Invaders Championship (figura 1) teve eventos regionais, em 1980, em Los Angeles, San Francisco, Fort Worth, Chicago e Nova York, e recebeu ampla cobertura da imprensa, atraindo mais de dez mil participantes ao todo (BOROWY; JIN, 2013; ELECTRONIC GAMES, 1982).

Figura 1 - National Space Invaders Championship de 1980

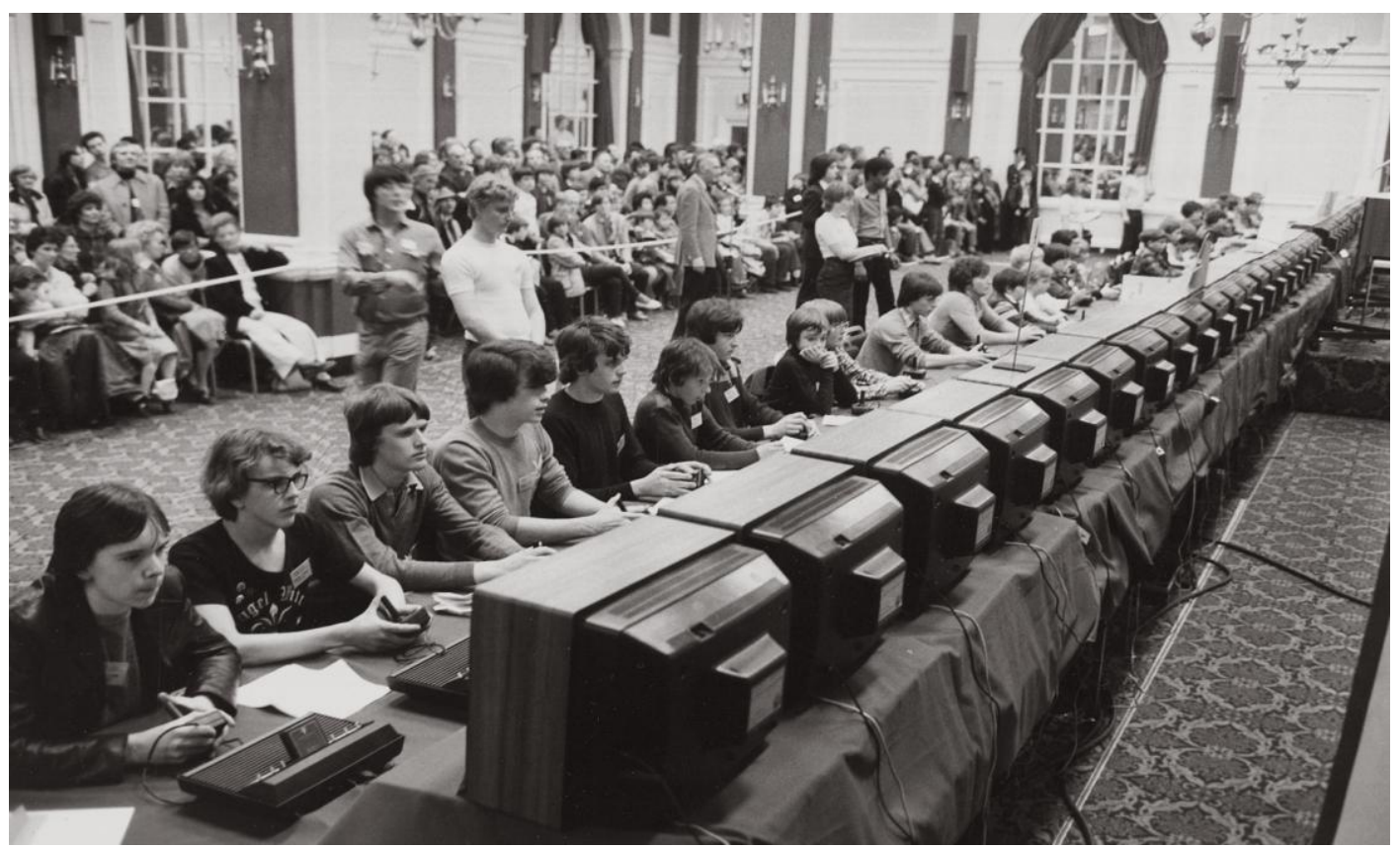

Fonte: Borowy e Jin (2013).

O pro gaming desenvolveu-se de forma proeminente a partir de meados da década de 1990, em decorrência da implementação das inovações tecnológicas e informacionais desenvolvidas nesse período, a exemplo das ferramentas de rede nos jogos para PCs. Os jogos em $L A N$ foram imprescindíveis para a constituição de uma comunidade de $e$-Sports. "O jogo em rede provou ser um elemento fundamental na história dos e-Sports [...]" (TAYLOR, T., 2012, p. 9, tradução nossa), na medida em que as tecnologias comunicacionais de suporte ao jogo (bate-papo em tempo real, canais de transmissão de áudio e vídeo, sites etc.) foram 
sendo criadas e sofisticadas ao longo dos anos.

Se os jogos de tiro e de espaçonaves foram os pioneiros do e-Sport, e não os jogos de luta como argumentado por T. Taylor (2012), a criação dos First Person Shooters (FPS) para computador pessoal (PC) certamente foi um marco no desenvolvimento do jogo profissional. A importância do papel de títulos como Doom (id Software, 1993) e Quake (id Software, 1996), como reforça T. Taylor (2012), é inegável, tanto pelo aspecto estrutural dos produtos quanto pelo desenvolvimento de comunidades ao seu redor. Ambos os jogos são considerados os responsáveis por um processo que incentivou consideravelmente o desenvolvimento de tecnologias de combate Player vs. Player (PvP). T. Taylor argumenta que a arquitetura multiplayer não era exclusiva dos títulos de FPS, mas tratava-se de um recurso frequente de jogos para $\mathrm{PC}$, nos quais distintos ambientes baseados na internet concebiam aos sujeitos uma forma de jogar e competir um contra o outro em escala praticamente global, embora o acesso à internet fosse bastante limitado no período.

Outro grande marco foi a criação da Cyberathlete Professional League (CPL) em 1997. A entidade, pioneira em competições profissionais de $e$-Sports, estabeleceu padrões para a organização de eventos, lucro, parcerias corporativas e patrocinadores para o campo (TAYLOR, T., 2012). 0 banqueiro Angel Muñoz, criador da CPL, é creditado como o responsável pela popularização e comercialização do termo ciberatleta, cuja origem data de meados da década de 1980-1990. T. Taylor (2012) considera tanto a CPL quanto seu fundador atores importantes no cenário dos esportes eletrônicos, que oferecera forma para os torneios funcionarem e a face pública dos jogos pro; para a autora, a CPL foi a vitrine dos jogos competitivos para o mundo exterior.

Contudo, segundo Borowy e Jin (2013), o e-Sport não tem origem necessariamente nos promotores das primeiras ligas competitivas da década de 1990: mesmo em meados de 1970, já existiam precursores da institucionalização do pro gaming como esporte - o evento All Japan TV Game Championships, realizado em Tóquio, no Japão, é um exemplo. Pode-se perceber, portanto, que subsiste uma controvérsia acerca da adoção do discurso de esportificação nos video games. Mais importante do que sublinhar datas e eventos é, contudo, perceber que esses são aspectos geracionais da cultura que hoje se estabelece, e que cada um, em sua particularidade, contribuiu para o contexto experimentado atualmente (figura 2). 
Figura 2 - Fase final do World Championship 2017 de League of Legends, no Estádio Nacional de Pequim, na China

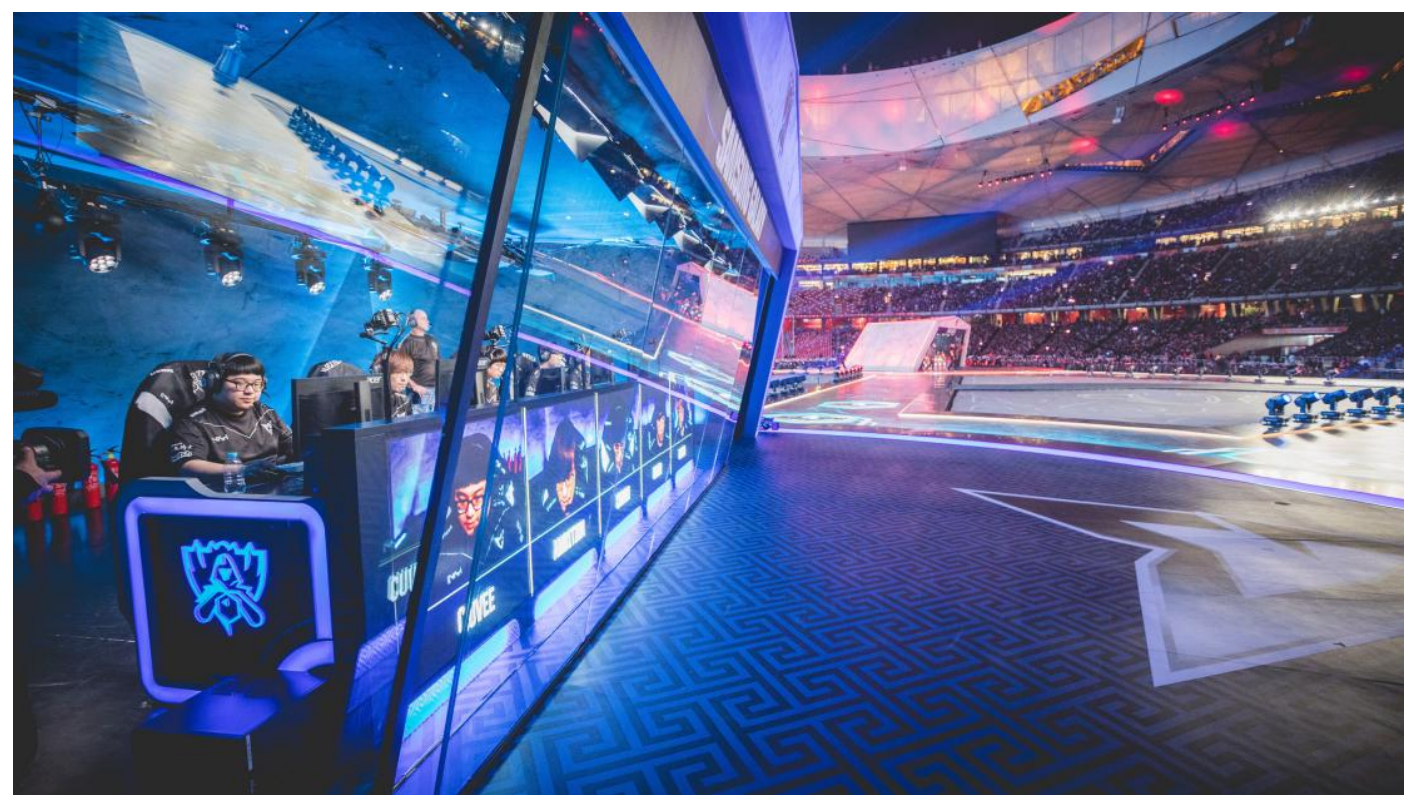

Fonte: Young-Wolff (2017).

Além disso, as primeiras experiências de torneios profissionais de arcades e consoles domésticos ecoam temas que ainda hoje são presentes nos e-Sports contemporâneos: o fascínio com as performances de alto nível e uma estruturação formal emergente de jogos digitais como esporte. "Embora nossa versão contemporânea dos e-Sports certamente pareça diferente de uma partida inicial de arcade, muitos dos mesmos desejos e desafios permanecem.", reforça T. Taylor (2012, p. 9, tradução nossa).

Como mostraremos à frente, muitas das ações precursoras ao longo da década de 1980 são fundamentais para o desenvolvimento do cenário dos jogos pro e para a ascensão da esportificação da atividade. Ademais, a progressiva atenção despendida recentemente à prática demostra que a indústria de video games vem incorporando vias mais maleáveis de consumo de eventos públicos. De fato, os jogos competitivos, desde seu surgimento, continuam a desempenhar um papel relevante tanto na cultura do jogo contemporânea quanto na indústria, especialmente nos dias atuais. No tópico que segue, empreenderemos uma discussão de ordem teórica acerca da relação entre $e$-Sports e esporte contemporâneo.

\section{E-Sport e esporte: pontos de convergência}

Um dos primeiros pensadores do esporte a se debruçar especificamente sobre o 
fenômeno dos e-Sports é Dennis Hemphill (2005), que, em seu trabalho, discute limites conceituais supostamente estáveis a partir da possibilidade desencadeada por lidar com o status do esporte em novas experiências e formas de conhecimento.

Hemphill (2005) foi um dos pioneiros a explorar a possibilidade de que as simulações de computador nos jogos digitais pudessem ser consideradas como esporte, embora seus enquadramentos do fenômeno ofereçam várias razões pelas quais as pessoas podem resistir à tese do ciberesporte. Qualquer mera menção que busque considerar os jogos digitais como uma forma de esporte é controversa, de acordo com o senso comum (BESOMBES, 2016a, 2016b; HEMPHILL, 2005; JONASSON; THIBORG, 2010), para o qual os jogadores são recorrentemente apresentados como frutos de desvios sociais (HEMPHILL, 2005).

Hemphill (2005) reconhece que existem diversos argumentos sociofilosóficos a favor do ceticismo sobre considerar jogos de computador como esporte, embora acredite que tais perspectivas são apenas um reflexo de estereótipos perniciosos que impedem que o enquadramento midiático acerca dos jogos digitais se transforme. A maioria dessas críticas sugere que as ações desempenhadas junto ao computador não são "reais", mas sim "virtuais" - ou seja, irrelevantes - e evocam um discurso que conduz à visão dicotômica ultrapassada acerca da realidade-ciberespaço do imaginário da cibercultura.

\subsection{Aspectos históricos e sociais dos esportes: o lugar do e-Sport na história e no futuro das práticas esportivas contemporâneas}

Ainda que, desde a virada do século XX, passou-se a associar o esporte como exclusivamente ligado ao desempenho humano, isso nem sempre foi assim. Uma primeira fase é marcada pela percepção violenta do termo, chamada de "inferno", difundida durante a Idade Média. A segunda é a fase da caça, decorrente de uma época conhecida como modernidade precoce ${ }^{9}$, na qual o esporte foi quase que unicamente relacionado a atividades que findavam com a morte de animais. A terceira denota a interpretação atual do termo, começando aproximadamente na passagem do século XX, chamada por Jonasson (2013, 2016) de fase "humana". 0 esporte moderno passa, nesse ponto de vista, a ser caracterizado por ser centrado, sobretudo, no humano.

\footnotetext{
${ }^{8}$ Aqui tomamos os termos ciberesporte, e-Sport e pro gaming como sinônimos. Para detalhes acerca destas nomenclaturas, ver Macedo (2018a).

9 Trata-se de um período histórico mencionado por Jonasson $(2013,2016)$ para endereçar e demarcar uma fase do esporte.
} 
Em suma, as visões do esporte apresentadas assinalam o quanto sua história é obscura e ambígua em muitos sentidos. Se uma percepção, por um lado, segue a acuidade do termo, encontrando a sua gênese na Europa medieval, por outro lado, atores individuais, como o barão Pierre de Coubertin, consideram a antiga Grécia como o berço virtuoso e glorioso do esporte.

Por sua vez, a percepção do papel dos jogos romanos como uma entidade que constitui a história do esporte, ao invés de sua constante invisibilidade até mesmo entre historiadores do esporte, demarca um exemplo de como a historicidade do fenômeno deve ser colocada continuamente sob escrutínio. Mas em que momento se poderia pensar em um lugar do e-Sport na história e no futuro do esporte? Para argumentar em favor desse aspecto, tornando possível a defesa do fenômeno como esporte, Jonasson (2016) apoia-se no raciocínio de Heather Reid (2011) para pensar os jogos romanos - as lutas de gladiadores e as corridas de carruagens - como antepassados do esporte moderno, oferecendo uma interpretação que os exime da marginalidade à qual a modernidade os relegou durante anos: na compreensão desses jogos, jaz seu legado para o esporte moderno.

Assim, no intuito de fornecer um espaço para o esporte eletrônico, Jonasson (2013, 2016) propõe uma analogia entre jogos romanos antigos e o $e$-Sport como duas instâncias de jogos públicos. Para ele, a percepção da relação atual entre o esporte e o jogo digital competitivo organizado assemelha-se ao enquadramento comum da dinâmica dicotômica entre os alegados vícios dos jogos romanos e as virtudes do atletismo grego. A forma pela qual os jogos romanos foram compreendidos em relação ao atletismo helênico (base para o advento dos esportes na Era Moderna) tem sua contrapartida no modo como os e-Sports (sendo descendentes dos ditos "infames" jogos romanos antigos) são entendidos em relação ao esporte. Assim, o jogo público contemporâneo, quando comparado ao atletismo grego ou ao esporte moderno, aparece frequentemente como uma prática desviante, violenta e invisível.

Nesse contexto, o jogo público surge, ao longo do percurso histórico do esporte, como um bastardo, uma vez que desencadearia uma controvérsia que a modernidade tratou durante muitos anos de purificar: a demarcação entre elementos humanos e não humanos mais frequentemente (JONASSON, 2016) ${ }^{10}$. Isso demonstra, por sua vez, que as diferentes modalidades esportivas e suas possibilidades de construção devem ser valorizadas e

\footnotetext{
${ }^{10}$ Embora os esportes e o atletismo sejam invocados com frequência, T. Taylor (2012) chama atenção para o fato de que a
} identidade do "jogador de computador" ser também o alicerce sobre o qual os e-Sports e a profissionalização são construídos. 
analisadas à luz da visão presente em seu próprio tempo, e não de outro. Mas o que essa afirmação denota? Ora, que se deve pensar em jogos digitais como e-Sports com base no momento atual, não por meio de critérios que possuíam utilidade para se referir a um mundo pregresso. Do mesmo modo, não é adequado que jogos antigos sejam analisados, como os romanos, com base em entendimentos contemporâneos do certo e o errado (JONASSON, 2016).

Se, por um lado, aceita-se um enquadramento discursivo de que o esporte é benéfico, proporcionando melhor saúde física e mental (HEMPHIL, 2005), por outro, o enquadramento acerca dos jogos digitais, criticado por pesquisadores como Lisbeth Klastrup (2003), costuma ser o do vício e da prática fútil11: um desperdício de tempo que favorece o sedentarismo e prejudica as relações sociais. Em contraste, o esporte organizado é tido como uma importante arena de socialização, embora também possua comportamentos desviantes, como trapaças e doping12 bioquímico (HUTCHINS, 2008; JONASSON, 2013, 2016). Como também percebe Besombes (2016a, 2016b), o discurso tende a contrastar os jogos digitais e atividades físicas e esportivas frequentemente. Ele demonstra, como também o fazem Jonasson e Thiborg (2010) e T. Taylor (2012), o quanto os discursos socialmente construídos acerca de ambas as práticas desenvolvem-se de forma dicotômica.

Um índice da legitimidade social do esporte é o fato de que, em esportes organizados, adultos têm a oportunidade de jogar sem que isso denote infantilidade: considere-se os jogos de futebol organizados Brasil afora, nos campos society, por exemplo, e a naturalidade com a qual se elogia o indivíduo que participa da prática. Por sua vez, o jogo digital competitivo é considerado uma atividade de lazer popular especialmente voltada para os jovens que não possui aceitação ou legitimação. Ainda assim, a análise de Jonasson e Thiborg (2010) reforça que o desenvolvimento do e-Sport adotou, e ainda adota, as características do esporte moderno como modelo desde seus primórdios. Como Jonasson (2013, 2016) percebe em seus estudos posteriores, há uma clara percepção, como discutiremos a seguir, de que o esporte eletrônico está longe de ser uma alternativa ao esporte moderno.

\footnotetext{
11 Este estigma, contudo, não vem da cultura digital. Ele advém do jogo, está em Johan Huizinga (1938) e demais autores, é uma acepção histórica de como o lúdico não dialoga bem com o trabalho. Para maiores discussões, atentar para o capítulo “Uma Operação de Contorno" em Thiago Falcão (2014).

12 O doping trata-se do uso de drogas ou de métodos determinados com o intuito de aumentar a performance de um atleta durante uma competição.
} 
Assim, mesmo que a legitimação social dos e-Sports pareça improvável, subsiste uma clara adoção do modelo do esporte como base para a constituição formal e estrutural do fenômeno (BOROWY, 2012; BOROWY; JIN, 2013; JONASSON, 2013, 2016). Acerca desse aspecto, que pode ser verificado tanto na produção dos torneios quanto em sua transmissão, Jonasson $(2013,2016)$ sublinha que, ao se utilizar desse modelo estrutural e formal, o $e$ Sport acaba por reforçar a hegemonia do esporte enquanto fenômeno social e midiático.

T. Taylor (2012), ao refletir sobre as imagens de jogadores competindo em campeonatos, questiona em que consiste o cerne do esporte: seria uma questão de fisicalidade? De perfeição de habilidades, de esforço ou alguma outra ação e empenho individual humano para se destacar? Nesse contexto, os $e$-Sports estão posicionados entre o jogo digital lato e o esporte. As noções de materialidade e de corpo estariam, assim, enraizadas no debate acerca do atletismo e esporte, embora não constituam parte central de nossa reflexão.

Contudo, é necessário apontar que, como qualquer conceito, a própria ideia de esporte depende do contexto social em que figura (COAKLEY, 2007). Assim, deve-se perceber que, por conta da popularidade dos jogos digitais e da forma como eles se apropriam de símbolos envolvidos na produção do esporte - dos pontos de vista de articulação estrutural, produtiva e midiática -, é concebível que essas competições impliquem na transformação da própria noção moderna e hegemônica de esporte. "0 fato de que essas competições são realizadas sob formas esportivas, como 'esportes', explica o rótulo 'Esporte Eletrônico' ou 'eSport'." (JONASSON; THIBORG, 2010, p. 288, tradução nossa).

Assim, o e-Sport está, por definição, relacionado à esfera esportiva. Todavia, essa aproximação implica também em uma negação ao estigma mencionado anteriormente. Jonasson e Thiborg (2010) propõem que o e-Sport seja descrito como um esporte dentro e por meio do ciberespaço, assumindo aspectos de esporte e de jogo digital competitivo, organizado profissionalmente.

\subsection{0 status da competição}

Ao longo dos últimos anos, há uma atenção crescente, nos Game Studies, ao debate acerca do e-Sport como uma competição dotada de uma determinada natureza que necessita de um esforço físico e/ou relevância motora por diversos autores (BESOMBES, 2016a, 
2016b; BOROWY, 2012; HEMPHILL, 2005; JONASSON; THIBORG, 2010; JONASSON, 2016; TAYLOR, T., 2012), embora outros considerem necessária uma verdadeira ruptura com essa percepção (HUTCHINS, 2008; JONASSON; THIBORG, 2010; JONASSON, 2013).

Embora Jonasson e Thiborg (2010) considerem essa discussão importante, ela também é problemática. Na medida em que maioria dos esportes necessitam de uma competência corporal, essa habilidade não será útil sem o exercício conjunto do intelecto - o que, por sua vez, demonstra a fragilidade da definição de esporte construída por Allen Guttmann (1978), responsável por impactar a forma com que a atividade é conceituada hoje, ao menos na academia.

A prioridade dada ao corporal e ao físico, no processo de distinção dos esportes de demais atividades lúdicas (incluindo os jogos), é proeminente na literatura filosófica e sociológica do esporte (BETTI, 2012; GUTTMANN, 1978; HEMPHILL, 2005; HÉAS; MORA, 2003; JONASSON; THIBORG, 2010; JONASSON, 2016). É essa relação corporal-motora, essa motricidade dominada pelas intencionalidades, que molda as formas culturalmente sistematizadas que hoje entendemos como esportes. É esse fato que se constitui como produto e processo de uma denominada cultura corporal de movimento (BETTI, 2012).

Todavia, se, por um lado, os esportes são tipicamente competições puramente físicas, e o xadrez, por outro lado, é estritamente intelectual, em que local no contínuo desses dois ideais o e-Sport deve ser alocado? Em relação a determinados esportes, como o futebol ou handebol por exemplo, o esporte eletrônico pode ser menos exigente fisicamente; no entanto, em relação ao atletismo de esportes finos de habilidade motora, os e-Sports definitivamente preenchem um vazio na família esportiva, ao privilegiarem uma coordenação de dedos e mãos.

A argumentação de Jonasson e Thiborg (2010) indica que os e-Sports estariam em uma zona de fronteira entre o esporte e as competições intelectuais. "Os e-Sports, embora intelectualmente exigentes, também dependem de habilidades físicas." (JONASSON; THIBORG, 2010, p. 290, tradução nossa). T. Taylor (2012, p. 38, tradução nossa) sublinha o mesmo: o "[...] domínio do corpo é crucial nos jogos pro, bem como nos esportes tradicionais.". No âmbito do e-Sport, a demanda por uma coordenação motora rápida e precisa entre mãos e olhos se sobressai como sendo uma habilidade lucrativa àqueles que almejam um destaque na comunidade competitiva.

A definição atual do esporte pode ser bastante estreita para capturar o "elemento esporte" no contexto do pro gaming, uma vez que o modelo de autores como Guttmann 
(1978), por exemplo, somente se concentra no esporte competitivo ou de conquista e, portanto, não em outras culturas corporais nas quais o e-Sport pode ser encontrado (HUTCHINS, 2008; JONASSON; THIBORG, 2010).

Segundo Kalle Jonasson (2016), uma questão central para os estudiosos do esporte é se ele deve ser definido com base em um conteúdo fluido e mutável ou como algo finito e substancial. Toda discussão acerca de como definir o esporte é atualizada a partir do advento dos e-Sports. Para o pesquisador, há uma dificuldade de identificar de onde e o que o esporte emana, e a incerteza que gira em torno de sua origem torna-o ainda mais difícil de delimitar.

Basicamente, a investigação do autor (JONASSON, 2016) concentra-se na forma de encaixar e tornar um lugar possível para o e-Sport dentro do corpus da própria história do esporte. Para o pesquisador, a fabricação do passado pode ser compreendida como algo decisivo para o esporte existir, embora sua história seja conceitualmente ambígua. Se o movimento do Barão Pierre de Coubertin, na busca por reviver as adormecidas Olimpíadas durante a virada do século XX, apelou para uma associação da disputa ao suposto atletismo glorioso da Grécia antiga de forma a promover um espírito fraterno entre os estados-nação participantes da competição (tornando o que hoje é chamado de esporte algo intrinsicamente associado às Olimpíadas da Grécia antiga), Jonasson (2016) questiona o porquê do $e$-Sport não ser igualmente comparado com uma prática antiga como o atletismo helênico.

A despeito disso, constantemente se argumenta que o $e$-Sport é algo completamente desviante do esporte moderno, sendo recorrentemente associado a uma prática sedentária ou talvez muito violenta no que tange ao seu conteúdo. Algo similar ocorreu com os espetáculos romanos da Antiguidade, considerados infames por suas violentas carnificinas, em comparação ao atletismo grego de outrora (JONASSON, 2016). Em seu estudo, Jonasson (2016) propõe historicizar o e-Sport como parte da história do esporte, aprofundando e matizando uma reflexão existente acerca da relação entre o jogo digital competitivo organizado e o esporte, particularmente dissertando sobre a possibilidade de existência de um lugar para esse fenômeno na história das práticas esportivas e, especialmente, que lugar poderia ser, além do fato de caracterizar - é o que acreditamos - uma entidade na história contemporânea do esporte.

Jonasson (2013) sugere que o $e$-Sport deve ser compreendido, realmente, como uma vanguarda às formas tradicionais do esporte moderno, sendo visto como um porvir 
inevitável dos esportes e do jogo (TAYLOR, T., 2012). 0 autor apresenta razões para discorrer acerca do termo esporte como constituído por uma dupla face cujas concepções largamente distintas subsistem concomitantemente: uma compreensão "restrita" e outra "ampla" do esporte. Segundo o pesquisador, ambas as interpretações existem tanto em diversidades legais quanto acadêmicas. Naturalmente, o discurso do e-Sport como uma atividade pouco saudável exerce uma pressão significativa no processo para torná-lo aceito e legitimado no cenário esportivo. Independentemente desse reconhecimento, ainda não há um consenso entre fortes associações internacionais do esporte, como o Comitê Olímpico Internacional (COI), para que a atividade seja aceita como uma modalidade esportiva.

Se, por um lado, subsistem determinadas aproximações entre o e-Sport e o esporte, bem como pontos de divergências, o que caracteriza a experiência de jogo que se agrega às dimensões do esporte, da mídia e da tecnologia que subjaz esse processo? Discutiremos essa questão a seguir, no intuito de elucidar parte da experiência social que se cria e se desenvolve entre jogadores engajados no jogo digital competitivo organizado.

\section{Experiência midiática e e-Sport}

A questão mais relevante que se coloca aos estudiosos dos $e$-Sports é que esse é um fenômeno híbrido e que deve assim ser considerado: mídia, tecnologia, jogo, entretenimento e, finalmente, esporte. Considerar o e-Sport como objeto implica assimilar a teia de relações que essa modalidade enseja e estabelece junto às TICs, aos media, ao entretenimento, ao jogo, ao esporte e à publicidade, entre outras esferas no contexto da comunicação e da cultura contemporâneas.

Nicolas Besombes (2016a, 2016b) argumenta que, à primeira vista, existem numerosas semelhanças entre o esporte eletrônico e o esporte moderno, de forma que subsiste um esforço por parte do mundo dos jogos digitais competitivos para a profissionalização de suas práticas e atores (HÉAS; MORA, 2003). Conforme já argumentamos, a apropriação de algumas das características de forma e estrutura esportiva por parte dos e-Sport busca emular códigos de uma prática social legitimada.

A abordagem de Besombes (2016a, 2016b), embora possua particularidades que a diferenciam e até se opõem ao trabalho de Jonasson $(2013,2016)$, assemelha-se ao esforço empreendido por Jonasson e Thiborg (2010) no desenvolvimento de uma comparação 
objetiva dessas duas práticas sociais, buscando dissolver o aspecto esportivo do $e$-Sport para chegar às questões centrais sobre a atividade.

Acerca dessa experiência midiática, Brett Hutchins (2008) oferece uma das primeiras tentativas sistemáticas de interpretar a inter-relação entre jogos digitais, mídia e esporte na contemporaneidade. Para ele, o e-Sport (seus eventos e seus atores, principalmente os ciberatletas) não pode ser explicado a partir de estudos independentes sobre os campos específicos do jogo digital, mídia, esporte, eventos ou competições esportivas organizadas. 0 fenômeno do jogo competitivo profissional reivindica uma compreensão necessariamente híbrida do e-Sport, “[...] um termo que significa a interpenetração contínua do conteúdo da mídia, do esporte e das tecnologias de informação e comunicação em rede." (HUTCHINS, 2008, p. 851, tradução nossa).

Essa proposição implica em uma mudança no pensamento acerca dos games e de sua relação com formas sociais e meios tradicionais de comunicação, argumentando em favor do desenvolvimento de uma sociologia da mídia que esteja atenta às transformações da atividade do jogo na Era da Informação. De maneira similar, Roger Silverstone (2002) defende que o jogo faz parte das dimensões e texturas da experiência e, ademais, afirma que a própria cultura popular sempre foi uma cultura lúdica. Para ele, o jogo precisa ser estudado como um relevante instrumento para análise da experiência midiática, assim como o próprio estudo da mídia reivindica uma atenção à brincadeira como sendo uma atividade central e nuclear no seio da vida cotidiana.

Para abordar a complexa interface entre a tríade jogos digitais, esporte e mídia, Hutchins (2008) desvia seu olhar das ênfases textual, narrativa e estética, abundantes nos Game Studies, ao contemplar essa tríade de aspectos no campo social mais abrangente, utilizando-os para demonstrar como relações e formas sociais são produzidas e transformam-se no decorrer do tempo. "Um resultado dessa estratégia é que o jogo competitivo organizado passa a ser tratado como muito mais do que uma moda passageira; em vez disso, representa o surgimento de um novo fenômeno, o e-Sport." (HUTCHINS, 2008, p. 854, tradução nossa). Isso implica, portanto, em uma reavaliação da relação entre jogo digital, mídia e esporte com o objetivo de melhor caracterizar a realidade da vida social contemporânea.

Embora a análise empreendida por Hutchins seja uma que busca relacionar, nesse contexto, o esporte moderno, transformações e rupturas não implicam necessariamente na sua obsolescência: ao invés disso, Hutchins (2008) acredita que tanto a agência das 
organizações quanto as atividades dos ciberatletas sinalizam para um fenômeno específico e original: "Este termo [e-Sport] foi inventado e entrou no uso (semi-)popular porque o jogo competitivo organizado representa tanto a continuidade quanto a descontinuação marcada com a relação estabelecida entre a mídia de transmissão e o esporte." (HUTCHINS, 2008, p. 857, tradução nossa).

O e-Sport nasceu na e da mídia, que altera os parâmetros de competição em termos de como ele é conduzido - na tela e no espaço digital - e a dinâmica do "jogo-competição" (Elias; Dunning, 1986) que, ao contrário do futebol ou do hóquei no gelo, é determinado por uma interface técnica e as possibilidades programadas contidas em um jogo de computador (HUTCHINS, 2008, p. 857, tradução nossa, grifo nosso).

A variedade de eventos de e-Sports sinaliza uma reorganização da fronteira entre tecnologia e atividade social com o surgimento de uma formação cultural relativamente "nova", o pro gaming. Segundo Hutchins (2008), é preciso pensar em termos de esporte como mídia (integração material) ao invés de esportes modernos (e tradicionais) e mídia (inter-relação estrutural). Conceber o esporte como mídia, portanto, implica compreender também o e-Sport como produto desses fluxos de mídia, comunicação e informação. Assim, o termo enfatiza uma dinâmica de mudança e ruptura com o domínio do esporte moderno enquanto uma unidade sociológica dotada de percepção.

Nessa amálgama, a competição intensa constitui-se em ambientes desenvolvidos digitalmente, e as correspondências entre jogadores e equipes são indissociáveis das redes de computação que fornecem a plataforma de competição. 0 pro gaming, portanto, é conduzido por meio de tecnologias de comunicação e computação em rede, o que é distinto do festival ou produto promovido pelos esportes modernos.

Apesar do e-Sport reconhecer a continuidade do jogo competitivo esportivo como um modelo organizacional e forma histórica, ele é também distinto ao criar um espaço necessário para explicitar o que há de diferente acerca dessa atividade - aqueles que fazem parte da comunidade em díspares níveis, como os próprios competidores, espectadores, coachs, analistas, comentaristas, narradores, managers, além dos milhares de outros participantes que não foram citados. Ou seja, trata-se de um termo que proporciona a continuidade da compreensão, auxiliando a conceituar as descontínuas características dessa atividade competitiva (HUTCHINS, 2008). 
Nesse cenário, o e-Sport deve ser compreendido enquanto um fenômeno sociotécnico emergente característico de uma mudança da sociedade mediante sua informatização (HUTCHINS, 2008). Importante perceber que a aparente flexibilidade do termo "esporte", sua constante atualização ao longo dos anos, poderia negar a necessidade da criação de uma nova expressão como o e-Sport. Pensar nessa perspectiva, contudo, implica em ignorar características que definem o pro gaming e, por sua vez, algo que nenhuma modalidade esportiva atual compartilha: “[...] a interpenetração material de conteúdo de mídia, esporte e computação em rede." (HUTCHINS, 2008, p. 864, tradução nossa).

O trabalho de Borowy e Jin (2013) evidencia o quanto aspectos estruturais dos esportes estão, intrinsecamente, envolvidos desde os primórdios da ascensão dos e-Sports. Isso denota que, ao passo que o reconhecimento dos arcades como o verdadeiro lugar de nascimento do movimento dos jogos digitais competitivos aumenta, há escassas discussões sobre sua experiência social e sobre como o pro gaming se ampliou como uma resposta à progressiva economia de experiência voltada para os eventos. Borowy e Jin (2013) defendem que os requisitos necessários para transformar a atividade em um esporte legítimo já se encontravam firmemente estabelecidos até meados da década de 1980, como um órgão de governo centralizado, a definição de diretrizes, a promoção e estímulo de uma competição leal e a manutenção de registros formais.

0 resultado desse movimento de incorporação de competições públicas de jogos resultou em uma fase prévia e midiatizada para os ciberatletas. Já naquele momento, defendem os autores, era possível que um jogador arcade profissional se tornasse uma celebridade, com patrocínio, fama e cobertura da imprensa. "À medida que a indústria de jogos arcades se expandia no início dos anos 1980, empreendedores astutos organizaram torneios de video games e começaram a construir um diálogo de institucionalização e profissionalização." (BOROWY; JIN, 2013, p. 2265, tradução nossa).

Embora o pro gaming tenha sofrido uma institucionalização esportiva parcial, a perspectiva contrasta com o atual cenário da indústria global de e-Sports, o qual sugere uma certa integração menos volátil e mais homogênea em algumas maneiras-chave do que nos últimos anos. Em parte, essa propagação e organização ocorre em decorrência da crescente popularidade de alguns títulos como League of Legends, segundo N. Taylor (2015) e Tarcízio Macedo (2018b), mas isso também decorre por conta do surgimento de serviços de 
transmissão ao vivo usados por muitos jogadores, equipes, organizações, guildas, entre outros, para divulgação de jogos competitivos.

Para além do advento desses serviços e da popularidade global de determinados títulos de jogos digitais, o crescimento dos e-Sports também se encontra fundamentalmente conectado ao desenvolvimento e diversificação das comunidades de base (TAYLOR, N., 2015; TAYLOR, T., 2012), responsáveis por tanto fornecer insumos na disseminação da prática, quanto na autorregulação e institucionalização do fenômeno. Enquanto que os primórdios indicam que o esporte eletrônico surgiu em ambientes públicos ou semipúblicos de $L A N$, arcades ou cybercafés, sua propagação também decorreu para outros contextos. Isso incluiria competições realizadas como parte de grandes grupos de $L A N$, com torneios em uma diversidade ampla de jogos e gêneros competitivos (TAYLOR, N., 2015).

\section{Considerações finais}

Defendemos neste artigo que o e-Sport pode ser compreendido como uma nova entidade social híbrida: uma que se compõe de forma interdisciplinar entre esporte, tecnologia, jogo digital, mídia e entretenimento, levando-nos a refletir acerca do conceito de esporte à luz da cultura digital. Para tanto, é relevante ter em mente que o conceito de esporte é dinâmico e dependente do contexto histórico no qual ele se enquadra. Na sociedade ocidental, por exemplo, o esporte moderno está vigorosamente relacionado ao mercado e aos processos de comercialização e globalização. Ademais, o exame do desenvolvimento do campo do esporte implica em perceber que o conceito é fruto de uma construção social, um reflexo da cultura que lhe dá origem, sendo historicamente datado e situado (BESOMBES, 2016a, 2016b; COAKLEY, 2007; GUTTMANN, 1978; HUTCHINS, 2008; JONASSON, 2013, 2016).

A percepção de um conceito deriva de seu invólucro histórico, cultural, espacial e temporal. Isso implica que a legitimidade do e-Sport depende do contexto e dos valores culturais e negociações pelas quais se constituem as ações humana e social em dado espaçotempo (TAYLOR, T., 2012). A noção do esporte como etapa de um processo histórico, presente no debate teórico empreendido em linhas anteriores, é um dos elementos fundamentais de sua caracterização; ela é, portanto, indissociável de um contexto representado em uma dada sociedade consolidada sobre uma base territorial historicamente determinada. O conceito de esporte eletrônico, assim, é inseparável das realidades e percepções de espaço e de sociedade: a continuidade e descontinuidade na 
construção dos conceitos de esporte e e-Sport não pode ser realizada senão no espaçotempo e pelo espaço-tempo.

Ao reconhecermos a natureza mediada e híbrida do pro gaming, a compreensão da prática segue a perspectiva de uma construção social mutável da experiência esportiva (e do conceito de esporte) no decorrer de um dado espaço-tempo (COAKLEY, 2007; JONASSON, 2013 , 2016). Ao invés de interpretarmos o e-Sport como uma variação adaptada de jogo e esporte moderno (AMÉRICO, 2014), propomos que o esporte eletrônico se configura como uma atualização e manifestação da prática esportiva para o contexto e como produto de uma determinada cultura contemporânea midiática e digital.

\section{Financiamento}

A pesquisa contou com o apoio da Coordenação de Aperfeiçoamento de Pessoal de Nível Superior (Capes), na modalidade bolsa de mestrado.

\section{Referências}

AMÉRICO, Marcos. 0 jornalismo esportivo transmídia no ecossistema dos esportes eletrônicos (E-Sports). Estudos em Jornalismo e Mídia, Florianópolis, v. 11, n. 2, p. 316327, jul./dez. 2014.

BETTI, Mauro. Educação Física, cultura e sociedade. Lecturas: educación física y deportes, Buenos Aires, v. 17, n. 174, 2012.

BESOMBES, Nicolas. Sport électronique, agressivité motrice et sociabilités. 2016a. Tese (Docteur de L'université Paris Descartes en Sciences et Techniques des Activités Physiques et Sportives) - Ecole Doctorale 566: Sciences du sport, de la motricité et du mouvement humain, Université Paris Descartes, Paris, 2016a.

BESOMBES, Nicolas. Les jeux vidéo compétitifs au prisme des jeux sportifs: du sport au sport électronique. Sciences du jeu, Paris, v. 5, n. 1, p. 1-20, 2016b.

BOROWY, Michael. Public gaming: eSport and event marketing in the experience economy. 2012. Dissertação (Master of Arts) - School of Communication, University of British Columbia, Burnaby, 2012.

BOROWY, Michael; JIN, Dal Yong. Pioneering eSport: The Experience Economy and the Marketing of Early 1980s Arcade Gaming Contests. International Journal of Communication, Los Angeles, v. 7, p. 1-21, 2013.

COAKLEY, Jay. Sport in society: Issues and Controversies. New York: McGraw-Hill, 2007. 
FALCÃO, Thiago. Não-humanos em jogo. Agência e Prescrição em World of Warcraft. 2014. Tese (Doutorado em Comunicação e Cultura Contemporâneas) - Programa de PósGraduação em Comunicação e Cultura Contemporâneas, Universidade Federal da Bahia, Salvador, 2014.

GUTTMANN, Allen. From ritual to record: The Nature of Modern Sports. New York: Columbia University Press, 1978.

HÉAS, Stéphane; MORA, Philippe. Du joueur de jeux vidéo à l'e-sportif: vers un professionnalisme florissant de l'élite?. In: ROUSTAN, Mélanie (dir.). La pratique du jeu vidéo: réalité ou virtualité? Paris: L'Harmattan, 2003, p. 131-146.

HEMPHILL, Dennis. Cybersport. Journal of the Philosophy of Sport, London, v. 35, n. 2, p. 195-207, 2005.

HUIZINGA, Johan. Homo Ludens: 0 Jogo como Elemento da Cultura. São Paulo: Perspectiva, 2001 (1938).

HUTCHINS, Brett. Signs of meta-change in second modernity: the growth of e-sport and the World Cyber Games. New Media \& Society, London, v. 10, n. 6, p. 851-869, 2008.

JONASSON, Kalle; THIBORG, Jesper. Electronic Sport and Its Impacto on Future Sport. Sport in Society: Cultures, Commerce, Media, Politics, London, v. 13, n. 2, p. 287-299, 2010.

JONASSON, Kalle. Sport Has Never Been Modern. 2013. Tese (Doctor of Philosophy in Food and Nutrition) - Department of Food and Nutrition, and Sport Science, University of Gothenburg, Nordenskiöldgatan, 2013.

JONASSON, Kalle. Broadband and circuits: the place of public gaming in the history of sport. Sport, Ethics and Philosophy, London, v. 10, n. 1, p. 28-41, 2016.

KLASTRUP, Lisbeth. Towards a poetics of virtual worlds: multi-user textuality and the emergence of story. 2003. Tese (Doctor of Philosophy in Digital Aesthetics and Communication) - Department for Digital Aesthetics and Communication, IT University of Copenhagen, Copenhagen, 2003.

MACEDO, Tarcízio. Like a Pro: Dinâmicas Sociais no e-Sport. 2018a. Dissertação (Mestrado em Comunicação, Cultura e Amazônia) - Programa de Pós-Graduação Comunicação, Cultura e Amazônia, Universidade Federal do Pará, Belém, 2018a.

MACEDO, Tarcízio. Dos teclados às arenas: o consumo do e-Sport como espetáculo. In: AMARAL FILHO, Otacílio; ALVES, Regina (org.). Espetáculos culturais na Amazônia. Curitiba: Editora CRV, 2018b, p. 175-200.

PARLEBAS, Pierre. Jeux, sports et sociétés, lexique de praxéologie motrice. Paris: INSEP, 1999. 
PLAYERS Guide To Electronic Science Fiction Games. Electronic Games, New York, v. 1, n. 2, p. 35-39, mar. 1982.

REID, Heather. Athletics and philosophy in the ancient world: contests of virtue. New York: Routledge, 2011.

SILVERSTONE, Roger. Por que estudar a mídia?. São Paulo: Edições Loyola, 2002.

TAYLOR, Nicholas. Power play: digital gaming goes pro. 2009. Tese (Doctor of Philosophy in Education) - Graduate Program in Education, York University, Toronto, 2009.

TAYLOR, Nicholas. Professional Gaming. In: MANSELL, Robin; ANG, Peng (ed.). The international encyclopedia of digital communication and society. London: Wiley Blackwell, 2015. v. 1, p. 987-990.

TAYLOR, T. L. Raising the Stakes: E-Sports and the Professionalization of Computer Gaming. Cambridge: MIT Press, 2012.

YOUNG-WOLFF, Colin. 2017 world championship finals stage. 2017.1 fotografia. $6720 \mathrm{x}$ 3780 pixels. Créditos e copyright para Riot Games @), Inc.

\title{
E-Sports, heirs to a tradition
}

\begin{abstract}
This article undertakes a historical discussion about the phenomenon of organized competitive digital game, popularly known as e-Sport. Its purpose is to provide a theoretical framework that addresses the hybrid aspect of e-Sports, considering that it converges the fields of Communication, Game Studies, Sociology and Philosophy of Sport. The article, which addresses e-Sport as the legitimate heir of a sport tradition, investigates two specific aspects of practice: (1) a genealogy which, in our belief, connects them to a millennial tradition; and (2) an ontology that underlines its necessarily mediatic experiential condition.
\end{abstract}

\section{Keywords}

Games. E-Sports. Sport. Competition. Game Studies. 